\title{
Hiroshi Yamamoto Named New JMR Associate Editor in Japan
}

Hiroshi Yamamoto of Nihon University began his tenure as associate editor in Japan for the Journal of Materials Research on January 1, 2001. He replaces Shigeyuki Sōmiya (Teikyo University of Science and Technology), who retired at the end of 2000 after 15 years of service to $J M R$. Yamamoto will oversee the submission and review of all papers submitted to the journal's office in Japan.

Yamamoto, who is on the faculty of Nihon in the Department of Electronic Engineering and Computer Science, received his Doctor of Science in Engineering degree from the Tokyo Institute of Technology in 1979. His research has been primarily in the area of electronic materials, focusing on processing and characterization of superconducting thin films and functional organic molecular thin films. Yamamoto has published more than 70 papers and has held several editorial positions over the course of his career. Included among these positions

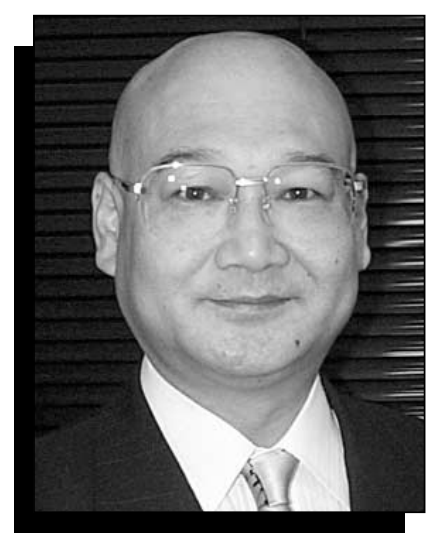

Hiroshi Yamamoto

are chief editor of the Materials Research Society of Japan News (1995-1999), editor of the Journal of the Institute of Electrical Engineers of Japan (1995-1996), and chief editor of the Fundamentals and Materials Division in The Transactions of the Institute of Electrical Engineers of Japan (1987-1988).
Commenting on the transition in editorship, Robert P. Frankenthal (Bell Labs/Lucent Technologies), Editor-inChief of JMR, said, "Hiroshi Yamamoto's impressive record both in research and in scientific publishing makes him the ideal person for this position. His extensive contacts in Asia will help to continue the tradition set by Professor Sōmiya in expanding $J M R^{\prime} s$ author and referee base on a global level."

Frankenthal expressed his appreciation for the dedicated service that Sōmiya provided to JMR for more than 15 years. "He greatly increased our presence in Asia," Frankenthal said, "and we are looking forward to working with Professor Yamamoto to give $J M R$ an even stronger presence around the world."

Yamamoto is now accepting submissions, which may be sent to him at Nihon University. Submission information is located on the JMR Web site at www. mrs.org/publications/jmr. 